\title{
Consumers Perception on Quick Service Restaurants
}

\author{
Datrika Venkata Madhusudan Rao, Narmada Kalgi, Neha Choudhary
}

\begin{abstract}
QSR mean restaurants that offer quick, effective, takeout prepared foods at sensible costs. The size of the coordinated Indian QSR market is \$ $167 \mathrm{bn}$. In light of the high populace and enormous extent of youth in India for QSR are flourish but it may, having openings isn't sufficient; they need to change over them into a beneficial business. Keeping in view the Indian propensities and changing inclinations towards food utilization, the principal reason for this research is to comprehend the business, recognize the basic factors that can influence the recurrence of client's visits to QSRs. As indicated by the research for the majority of the respondent's quality food is one of the key variables which first rings a bell when they think about their most favored QSR. Neatness, food assortment, quality, administration, seating space, healthy benefit, and scrumptious food are significant components that assume a significant part in building client insight about the QSR. The greater part of the respondents visits QSR for reward and investing energy with family and furthermore for unwinding. The primary goal of the examination is to contemplate the shopper's discernment towards Quick Service Restaurants (QSR) which empowers us to comprehend buyer's conduct. The utilization example of shoppers causes us to comprehend their inclinations. This examination is exploratory in nature and has utilized a cross-segment time skyline since it comprises of meetings completed in a limited ability to focus time through a survey having 20 closed questions from the example populace of 200 individuals picked by irregular inspecting strategy. The information gathered is investigated utilizing pie diagrams, rate examination, and chi-square. The investigation helps in giving significant ramifications to QSR arranging and tasks. This examination depends on information gathered through surveys and investigation. This research will help the key QSRs how they should deal with get more clients and to improve client faithfulness.

Keywords: Quick Service restaurants, Fast food, Eat out, Service and Quality
\end{abstract}

\section{INTRODUCTION}

When the economy is encountering a stoppage and numerous areas are attempting to grow, one area that has developed quickly is QSR. The whole Indian food market can be ordered into two sections: Organized and Unorganized Restaurant market. The sloppy eatery market incorporates side of the road merchants, Dhabas, vans, and so on the QSR, Pubs, Bars, Clubs and Lounges, and the food courts and kiosks. The QSR market will twofold to around Rs 167 billion in 2019 from Rs 49 billion out of 2016, driven generally by new store increases.

Manuscript received on March 09, 2021

Revised Manuscript received on March 15, 2021

Manuscript published on March 30, 2021.

* Correspondence Author

Dr. Datrika Venkata Madhusudan Rao*, Professor, Department of Management, Jain University, Bangalore (Karnataka), India.

Dr. Narmada Kalgi. Assistant Professor, Department of Management, Jain University, Bangalore (Karnataka), India.

Dr. Neha Choudhary, Assistant Professor, Department of Management, Jain University, Bangalore (Karnataka), India.

(C) The Authors. Published by Blue Eyes Intelligence Engineering and Sciences Publication (BEIESP). This is an open access article under the CC BY-NC-ND license (http://creativecommons.org/licenses/by-nc-nd/4.0/)
In a particularly deft climate, how many advantages a specific QSR can benefit; depends upon their own advertising procedures, the amount they get clients, and their taste and inclinations. Fast administration eateries are additionally named drive-through joints. Inexpensive food implies sensibly evaluated and promptly accessible food that is by and large high in calories, fat, salt, and sugar. Also, one of the key variables bringing about eatery development is experimentation with new arrangements, subjects, and menus by inventive and innovative endeavors as per the affiliation. QSR industry is one of the vital portions of the Indian food administration market and is becoming extremely quick. Significant reasons for its development are: More youthful labor force, changing way of life, desiring in Indians for worldwide food, New Themes and menus by inventive and enterprising endeavors, Expanded working ladies. Its business comes from principal metros and smaller than normal metros on account of shopper's mindfulness about them changed life style. Despite the fact that it has begun creating a business from the country market in view of the improved street network, urbanization. Once a reclusive, home-driven customer, the liberal Indian is today awakening to a beginning yet impressive "Eating Out" culture, making food administrations quite possibly the most encouraging business areas in India. Indeed, even with a commitment of only $2.3 \%$ to India's GDP, the Food Services market is worth INR 247,680 crore (USD 48 billion). Further, the market is projected to develop to INR 408,040 crore (USD 78 billion) in the following 5 years, i.e., by 2020 . When the economy is encountering a log jam and numerous areas are attempting to grow, one area that has developed quickly is coordinated cheap food outlets (speedy assistance eateries). The idea of fast help eateries was first presented in the US. These cafés are progressively turning out to be helpful spots for youngsters, families, and youthful working experts to mingle. Brisk Service Restaurants are unique sorts of cafés and structure a vital piece of the Indian Food Service Industry. QSRs have both cheap food cooking styles and negligible table administrations to oblige the requirements of different young people and working experts. The separating element of these eateries is the speedy conveyances of food things which are a fundamental part for the working populace of an agricultural nation like India.

QSRs for the most part target individuals in the age section of 16-35 years, as this is the age section keen on tasting new cooking styles and having quick nourishments consistently. These eateries can work everywhere on an area as a piece of chain cafés or can be under establishment activities, which arrangements normalized fixings and additionally part of the way arranged food sources and supplies to every eatery through controlled inventory channels.

Blue Eyes Intelligence Engineerin \& Sciences Publication (C) Copyright: All rights reserved.

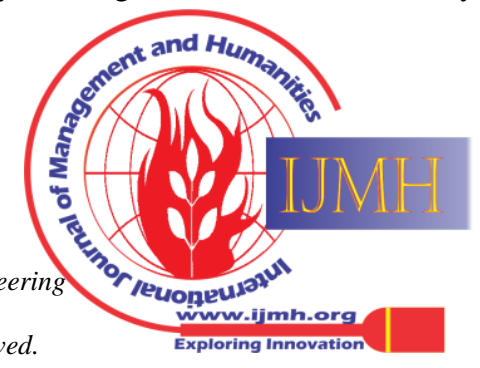




\section{Consumers Perception on Quick Service Restaurants}

The QSR section however is a huge portion of the Indian Fast-food benefits yet is nearly incipient and has a ton of extension for development in India. In India, an enormous number of global QSRs have set up their outlets with the establishment privileges of different organizations. Indian QSRs are additionally coming up and growing however unfamiliar brands keep up their predominance. McDonald was the first QSR in Quite a while followed by different others like KFC and Dominos.

\section{REVIEW OF LITERATURE}

Ali et al. (2020) found that improving client relationships could give an edge to cheap food retailers in India if they can oversee and detail new promoting apparatuses and practices to encourage more prominent client fulfillment and better general insight. Goyal and Singh (2017) have finished that youthful clients visit inexpensive food channels for no particular reason and change. In information screen's (2015) study cheap food market is characterized as the offer of food and beverages for sure-fire utilization either on the premises or on assigned regions imparted to other foodservice administrators or for utilization somewhere else. Gupta (2013) found that client discernment, taste, and fulfillment grow more ideal shopper conduct towards a specific brand than some other factor. Joined country monetary and social commission for Asia anticipated that by 2020 half of the absolute populace would be metropolitan; half of that populace would be from Asia. So inexpensive food organizations have been accepting it as an open door to serve Asian nations like India, Pakistan.

Ragavan (2013): "Food in a globalized world" has presumed that food is a method forever yet it has become important speculation for business Kotler (2009) Stated that the center reason for any cheap food retailer should be identified with offering some benefit for cash to its clients and utilize progressed promoting and correspondence channels to reinforce the general advertising crusade.

\section{OBJECTIVES OF THE STUDY}

1. To know the factors influencing consumer perception towards QSR.
2. To understand the behavioral patterns of consumers towards QSR.

3. To study the purchase pattern of customers towards QSRs from the view point of gender, marital status and occupation of customers and number of times they visit the QSRs

The purpose of this project is to "investigate consumer behavior and perception towards Quick Service Restaurant (QSR). The project also explores the most influential factor through consumer demographic which includes age, gender, income and level of education.

\section{RESEARCH PROBLEM}

The study aims to know, what is the driving force or the reason behind the fast-food consumption of the Indian consumer in QSRs?

\section{METHODOLOGY}

This exploration is both illustrative and descriptive in nature utilizing both primary and secondary information. Essential information is gathered utilizing an organized poll comprising of 20 close-ended questions and one openfinished inquiry. Optional information sources incorporate books, diaries, and sites. This investigation tried to contemplate and break down shopper conduct and insight as to QSRs in twin urban areas Hyderabad and Secunderabad. The sample size is restricted to 200. The Primary information has been gathered utilizing a poll from the example populace of 200 individuals predominantly from the geological territory of Hyderabad and Secunderabad chose through the Convenient Sampling strategy. The information of the examination is investigated with Pie Charts, Percentage investigation, and Chi-square.

\section{RESULTS AND DISCUSSION}

Testing of the Hypotheses

\section{Gender of the consumer and frequency of visiting QSR.}

Ho (1) = There is no relationship between gender of a consumer and the frequency of visiting QSR.

Ha (1) = There is a significant relationship between gender of a consumer and the frequency of visiting QSR.

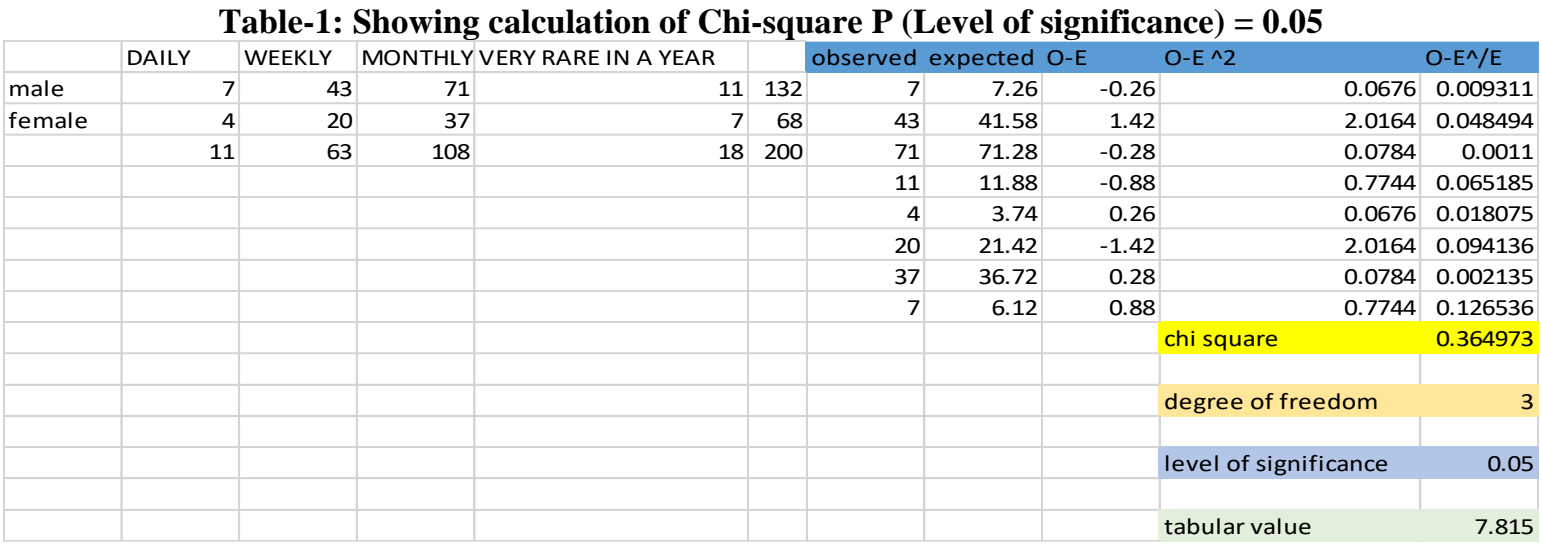

From the table 1 it is interpreted that: -

Pearson Chi Square - 0.3649, Degrees of freedom - 3, Tabular Value - 7.815. 
Since, chi-square value (0.364973) is less then tabular value (7.815). Thus, it can be inferred that there is no significant relationship between gender and the frequency of visiting QSR.

\section{Marital status and Frequency of visiting QSR}

Ho (2) = There exists no relationship between marital status of a person and the frequency of visiting QSR. Ha (2) = There exists a significant relationship between marital status of a person and the frequency of visiting QSR.

Table-2: Showing calculation of Chi-square $P$ (Level of significance) $=0.05$

\begin{tabular}{|c|c|c|c|c|c|c|c|c|c|c|}
\hline \multirow[b]{2}{*}{ married } & \multirow[t]{2}{*}{ daily } & \multirow{2}{*}{$\begin{array}{r}\text { weekly } \\
10\end{array}$} & \multirow{2}{*}{$\begin{array}{r}\text { monthly } \\
19\end{array}$} & \multicolumn{2}{|c|}{ very rare in a year } & \multicolumn{2}{|c|}{ OBSERVE[ EXPECTED } & \multirow{2}{*}{$\begin{array}{l}\text { O-E } \\
1.19697\end{array}$} & $O-E^{\wedge} 2$ & \multirow{2}{*}{$\begin{array}{c}\mathrm{O}-\mathrm{E}^{\wedge} 2 / \mathrm{E} \\
0.794627\end{array}$} \\
\hline & & & & 2 & 34 & 3 & 1.803030303 & & 1.432736455 & \\
\hline unmarriec & 4 & 33 & 52 & 9 & 98 & 10 & 11.07575758 & -1.07576 & 1.157254362 & 0.104485 \\
\hline & 7 & 43 & 71 & 11 & 132 & 19 & 18.28787879 & 0.712121 & 0.507116621 & 0.02773 \\
\hline & & & & & & 2 & 2.833333333 & -0.83333 & 0.694444444 & 0.245098 \\
\hline & & & & & & 4 & 5.196969697 & -1.19697 & 1.432736455 & 0.275687 \\
\hline & & & & & & 33 & 31.92424242 & 1.075758 & 1.157254362 & 0.03625 \\
\hline & & & & & & 52 & 52.71212121 & -0.71212 & 0.507116621 & 0.00962 \\
\hline & & & & & & 9 & 8.166666667 & 0.833333 & 0.694444444 & 0.085034 \\
\hline & & & & & & & & & chisquare & 1.578531 \\
\hline & & & & & & & & & & \\
\hline & & & & & & & & & DEGREE OF FREEDOM & 3 \\
\hline & & & & & & & & & LEVEL OF SIGNIFICANCE & 0.05 \\
\hline & & & & & & & & & TABULAR VALUE & 7.815 \\
\hline & & & & & & & & & & \\
\hline
\end{tabular}

From the table 2 it is interpreted that: -

- $\quad$ Pearson Chi Square - 1.5785

- Degrees of freedom - 3

- Tabular Value - 7.815

The chi-square value (1.57) is less than tabular value (7.815). So, there is no significant relationship between marital status and frequent visit to QSRs.

\section{Occupation and Frequency of visiting QSR}

Ho (3) = There exists no association between occupation of a person and the frequency of visiting QSR. Ha (3) = There exists an association between occupation of a person and the frequency of visiting QSR.

Table-3: Showing calculation of Chi-Square $P$ (Level of significance) $=0.05$

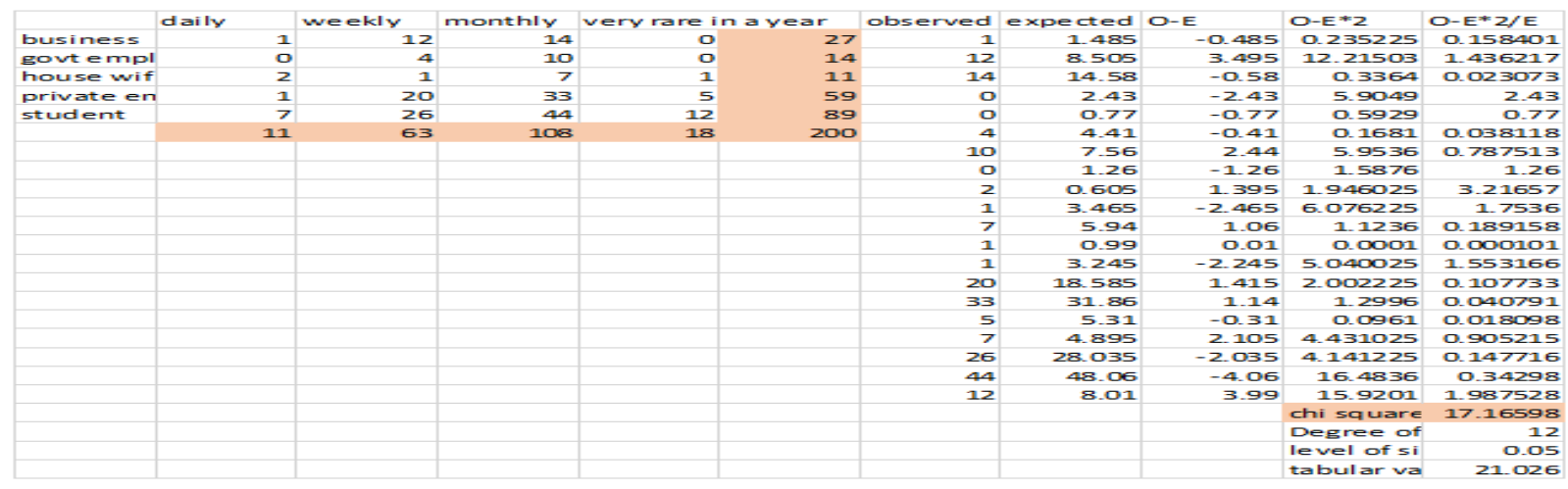

From the table 3 it is interpreted that: -

- $\quad$ Pearson Chi Square - 17.16598

- $\quad$ Degrees of freedom -12

- Tabular value -21.026

As Chi-Square value (17.16598) is less then tabular value (21.026), there exists no association between occupation of a person and the frequency of visiting QSR.
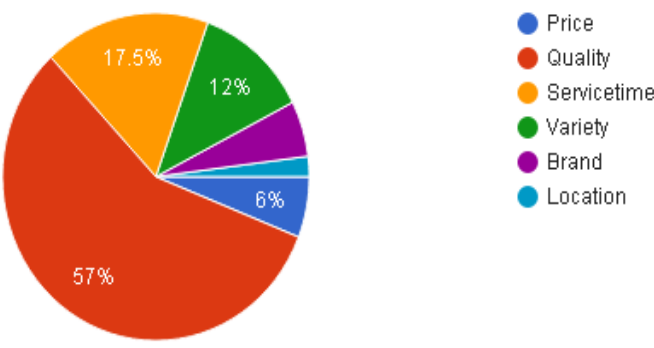

Fig.1 showing reason for making a particular QSR as customer's favorite.
Published By:

Blue Eyes Intelligence Engineering \& Sciences Publication (C) Copyright: All rights reserved.
To eat good food

To eat something different, food I don't often eat

Do not want to cook

- For special events (birthdays,

Valentine's Day, anniversary, etc.)

Non-chosen situation (professional,

Fig.2 showing main reasons for visiting to QSRs by customers.

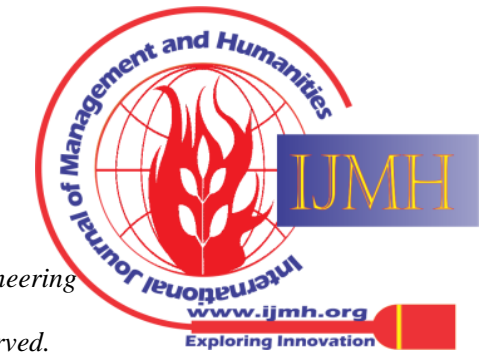




\section{Consumers Perception on Quick Service Restaurants}
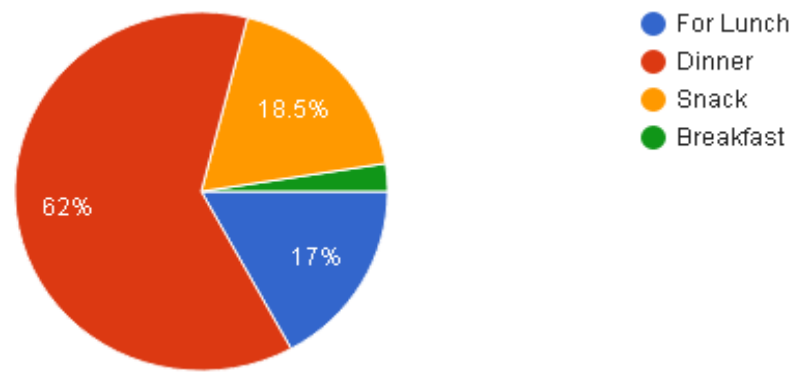

Fig.3 showing most preferred which meal in QSRs

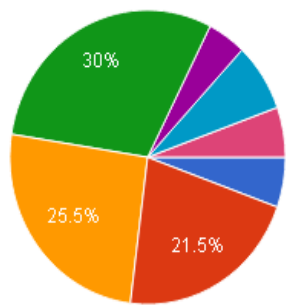

$$
\begin{aligned}
& \text { Variety of dishes } \\
& \text { Affordable prices } \\
& \text { Meal deals } \\
& \text { Food quality (with quality ingredients } \\
& \text { Variety of drinks } \\
& \text { Fast service } \\
& \text { Easy access }
\end{aligned}
$$

Fig.4 expectations of the customers from the QSRs.

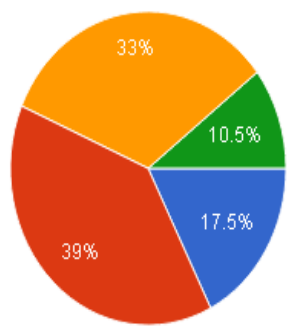
Recommendations by relatives
(word of mouth

Reviews on Internetimagazines

To discover a different kind of cuisine, original food

Affordable prices, cheaper than other restaurants

Fig.5 showing the reasons for trying new QSRs

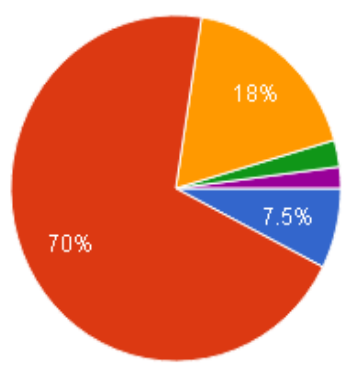

Less than $2 \mathrm{Kms}$

$2-5$

5-10

10-20

More than 20

Fig.6 showing the preferred distance to visit QSRs

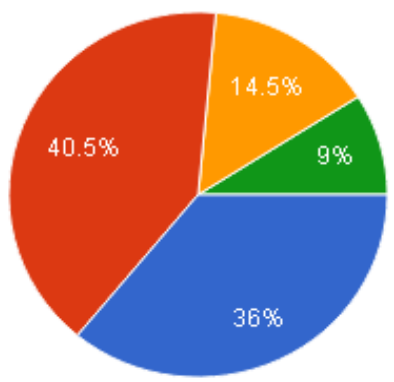

Taste

Quantity

Ambiance

Service

Fig.7 showing reasons for satisfaction with QSRs

\section{CONCLUSION}

According to the survey QSR should offer more food varieties as only $36.5 \%$ of the respondents find food offered by QSR different. It is also suggested that QSR should maintain food quality as only $30 \%$ of the sample population feel that food quality is good at QSRs. And these restaurants should work on their review systems as only 39\% of the sample population are influenced while making the decision to visit QSR or not. QSRs should make effort to open more franchise restaurants as $70 \%$ of the sample population prefer QSRs within 2-5Kms of their distance range and also should improve its seating capacity as customers (64\%) prefer to wait only 5-10 minutes. The study can't be summed up as the information has been gathered uniquely from the geological region of Hyderabad and Secunderabad. Singular reactions might be one-sided here and there. As indicated by the review directed McDonald's is the most favored QSR followed by KFC and Paradise is the most visited QSR followed by Bawarchi so the QSRs should offer more food assortments and ought to likewise deal with the quality by furnishing them food with more dietary benefit.

It is additionally seen from the investigation that the food needs of the clients during breakfast are dismissed and ought to be dealt with by all QSRs. They should likewise offer food reasonable to all age bunches as the majority of the clients visiting QSRs fall in the age gathering of 20-35. the food needs of the children and elderly folks' individuals are dismissed.

\section{REFERENCES}

1. Anita, N and Radhika, S. 2013. A Study on Consumer Behavior towards Instant Food

2. Products in the Modern Era. JIMS. 28-31. A Brief Report on Food Processing Sector in India,

3. ASA \& amp; Associates. October 2013. http://www.asa.in/pdfs/surveys-reports/Food- Processing-Sector-inIndia.pdf.html

4. Alok Kumar Rai, Srivastava Medhat 2013. The Antecedents of Customer Loyalty in Journal of Competitiveness Vol. 5, Issue 2, pp. 139-163, June 2013.

5. Bale Swamy, M., Anil Kumar, T and Srinivasa Rao, K. 2012. Buying Behavior of Consumers towards Instant Food Products, International Journal of Research and Computational Technology. 2(2): 1-13.

6. Ekta Jain, A. 2009. Study on consumer perception towards instant food products. MBA Thesis. Bangalore University, Bangalore, India

7. Heena Upadhyay and Rajni Parthenia. 2013. Consumer Expenditure Behavior in India: A Case of Rural and Urban Consumer. International Journal of Business and Management Invention. 2(2):68-73.

8. Praveen Babu Chiridotid 2015, A Study on Consumer Purchasing Behavior of Instant Food Products in Andhra Pradesh. krishikosh.egranth.ac.in/bit stream/1/80111/1/D9799.pdf

9. Krupskaya, A and Arjuna, C. 2012. A study on consumer buying behavior towards instant food products in Coimbatore. Nomex International Journal of Management Research. 2(2): 23-30

10. Kavitha, T.C 2012. A comparative study of growth, challenges and opportunities in QSR of rural market. Management Review. 2(3): 2328.

11. Palekar Apoorva. 2004. Consumer preferences in purchase of ready to eat snacks- Branded potato chips. Indian Journal of Marketing. 34(9): 34-38.

12. Pura, R., and Sanghera, J. value 1989. Nutritive and consumption pattern of some processed foods. International Journal of Marketing. 46(6): 24-27.

13. Rees, A. (1992). Factors Influencing Consumer Choice. International Journal of Dairy Technology, 45(4), 112-116
Published By:

Blue Eyes Intelligence Engineerin \& Sciences Publication (C) Copyright: All rights reserved.

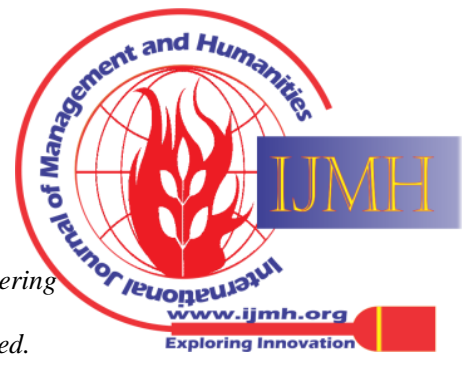




\section{AUTHOR (S) PROFILE}

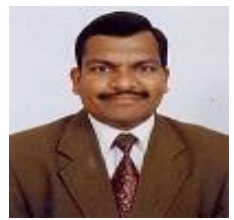

Dr. Datrika Venkata Madhusudan Rao, MBA, MPhil, PhD, MSc. (Psy), UGC-NET, APSET, PGDFTM, PGDIPR, DCA, CCPSA, MCIM(UK), Affi. $\quad$ CIPD(UK).Professor-Management in Jain University, Bangalore. His M. Phil \& Ph. D- area is "Consumer Behavior". His current research interests include Consumer Behavior, and New-Age Marketing Practices. His teaching areas are Consumer Behavior, Strategic Management, Marketing Research, Environmental Science, Gender Sensitization and IPRs. He has a blend of Teaching and Industry experience of 26 years. He had worked as an educator with different Government Universities and Ministries in Eritrea, Ethiopia and Bahrain for approximately 13 years. He has 14 articles and 4 books to his credit. He is Editor of IJBMR and Advisory/ Editorial Board Member of IJREM, IJAAS (USA), EBM (USA), JEE (USA), IJBM(EU), IJTMR (Ghana), IJAAC, IAAC, IJDERS, RAYS: JRCM Journals and ICRDTIET-2020, ISERT2020 conferences; Member of British Council, MOE, Eritrea, Harvard Business School Publishing, and SHRM Consultants. He has won the Distinguished Educator Award 2019 by IBAE at Dubai; Best Senior Faculty Award 2019 by Novel Research Academy at Pondicherry; and a Memento by UNMEE

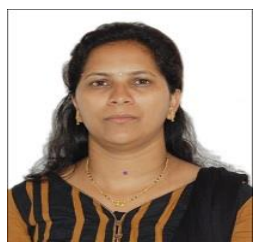

Dr. Narmada Kalgi, Ph.D. in Management on the topic "Measure of effectiveness of Employee Engagement Programs with Special reference to IT companies (A study of Selected IT companies in Bengaluru) from Gulbarga University. MBA in Human Resource and Financial Management from Gulbarga University. BE in Industrial Engineering and Management from Bangalore University. KSET in Management. CIPM Certified from AIMA on 'Totality of Project Management. She has around 15years of experience, 7 years as a corporate HR having worked on entire gamut of HR as HR Business Partner cross IT Industry and around 8 years of experience as teaching in the capacity of Part time Faculty/ Freelance trainer with various colleges and companies. Worked with Team-lease as a trainer and worked with colleges like TIMS, NSB, ISBR, IBMR and Oxford College of Management as a faculty. She is Presently Associated with Jain University as Assistant Professor.

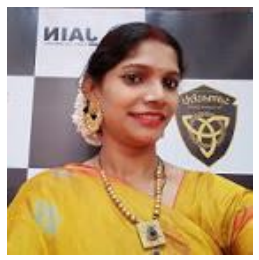

Dr. Neha choudhary ph.d., ugc-net, mba, b.sc Completed $\mathrm{PhD}$ on Employees Job Satisfaction, with reference to Job Involvement and Organizational commitment in service sector of Gorakhpur, from Deen Dayal Upadhyay University, Gorakhpur. A quality-oriented professional with 5 years and 3 months of experience in Teaching. Experienced in developing curriculum and syllabus for PGDM. Experience \& skills in developing curriculum to accommodate different learning styles \& maximizing students' comprehension; conducted various Workshops, Training \& Seminars and organized various conferences. Qualified UGCNET twice, in Management in 2012 and in Human Resource, Industrial relation, Personnel management, Labor law and welfare 2011. Qualified CET- PhD Exam in 2012. Multiple Research Paper Presented and Published in National Seminar and Conferences. Attended more than 30 FDP and conferences (International and National). Completed 5 Coursera program. Completed 3 MHRD FDP MOOCS by Delhi University. Completed 7 linked learning courses. One research paper is published in UGC care list - "Wesleyan Journal of Research" with ISSN(P) :0975-1386. One research paper published in Scopus-indexed journal-Psychology and Education Journal, Customers Buying Behavior and Preference Towards International Branded Sports Shoes, VOL. 57 NO. 9 (2020): VOLUME 57 NO. 9 (2020).

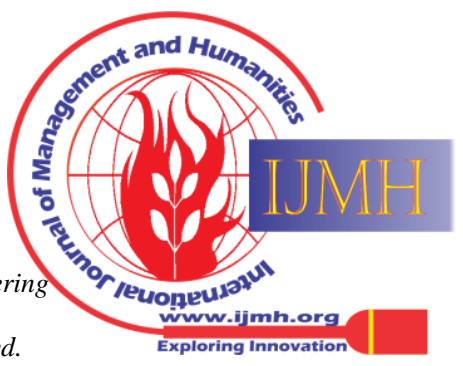

